\title{
Low-temperature thick-film dielectrics and resistors for metal substrates
}

\author{
C. Jacq, Th. Maeder, S.Vionnet, P. Ryser
}

EPFL, Laboratoire de Production Microtechnique, CH-1015 Lausanne, Switzerland

\begin{abstract}
In this work, a set of low-temperature thick-film dielectrics consisting of two high-lead lowtemperature glasses, stabilised by various amounts of alumina filler, is characterised on alumina and aluminium metal, as a function of firing temperature. Corresponding resistors based on the same glasses as the dielectrics, but with $\mathrm{RuO}_{2}$ as a conductive phase, were studied on the dielectrics. The purpose of these materials is to enable deposition of thick-film electronics onto substrates such as glass and metals (steel, aluminium, brass, titanium), which cannot be exposed to the standard high-temperature $850 \mathrm{C}$ thick-film firing cycle. Satisfactory insulating properties were obtained, and the properties of the resulting resistors are promising, but managing thermal mismatch was found to be a major issue regarding the mechanical integrity.
\end{abstract}

Keywords: Electrical properties; Thermal expansion; Glass; $\mathrm{Al}_{2} \mathrm{O}_{3}$; Sensors

Published in: $\quad$ Journal of the European Ceramic Society 25 (12), 2121-2124, 2005.

(Proceedings of Electroceramics IX, Cherbourg, Université de Caen, 31.5-3.6.2004)

Link: http://hdl.handle.net/10.1016/j.jeurceramsoc.2005.03.224

\section{Introduction}

Thick-film technology applied to piezoresistive force or pressure sensing typically uses alumina as a substrate material because it is the standard for thick-film technology [1]. However, alumina is not optimal for piezoresistive sensing applications, as its elastic modulus is high and its strength rather low. Additionally, alumina is brittle and therefore ill suited to harsh environments and its heat dissipation capabilities are limited. Aluminium or aluminium alloys offer advantages in applications such as high power electronics or high-range load cells, due to their excellent thermal dissipation, mechanical sturdiness, easy packaging and adjustable thermal expansion coefficient $\alpha$ (Al-Si and Al-SiC systems) [2,3]. However, the high temperatures associated with commercial thick-film processing $\left(850^{\circ} \mathrm{C}\right)$ are not compatible with aluminium owing to its low melting point: an appropriate low-temperature thick-film system (dielectrics, resistors and conductors) is therefore necessary.

In this work, we endeavour to investigate a novel low-temperature thick-film dielectric + resistor systems. In order to avoid interdiffusion problems between the dielectrics and resistors, both are based on the same glasses, differing only by the nature of the filler: $\mathrm{Al}_{2} \mathrm{O}_{3}$ for the dielectrics and $\mathrm{RuO}_{2}$ for the resistors. We present the results of the properties of the dielectrics (adhesion, mechanical integrity, dielectric strength, dielectric constant and loss) 
and the resistors (value, temperature coefficient of resistance - TCR), on alumina and aluminium substrates.

\section{Experimental}

In this work, seven thick-film dielectric materials based on 2 lead borosilicate glasses (V6 and V8) were evaluated, with different glass compositions, filler loadings and processing temperatures. Glass V6 is $75 \% \mathrm{PbO}+10 \% \mathrm{~B}_{2} \mathrm{O}_{3}+15 \% \mathrm{SiO}_{2}$, with $2 \% \mathrm{Al}_{2} \mathrm{O}_{3}$ added. Glass $\mathrm{V} 8$ is $85 \% \mathrm{PbO}+10 \% \mathrm{~B}_{2} \mathrm{O}_{3}+5 \% \mathrm{SiO}_{2}$, also with $2 \% \mathrm{Al}_{2} \mathrm{O}_{3}$ (all compositions by mass). Both glasses were melted 3 times and the resulting frit was subsequently ball milled to ca. 1 ...5 $\mathrm{mm}$. Dielectrics were prepared by adding various alumina powder concentrations to the glass powders and an organic vehicle, and the resulting mix was homogenised with a three-roll mill. Typical firing temperatures for materials based on $\mathrm{V} 6$ glass is around $600^{\circ} \mathrm{C}$, and around $500^{\circ} \mathrm{C}$ for those based on V8 glass. The alumina filler serves to improve the dimensional stability of the dielectrics. A commercial low-firing conductor composition (ESL $590 \mathrm{G}$, silver with glass frit) was chosen as top conductor for characterisation of the dielectric, and as resistor termination material.

A single thick-film resistor composition, based on the V8 glass, was prepared in the same way as the dielectrics, except that an usual conductive oxide filler for thick-film resistors [4], $\mathrm{RuO}_{2}$ (Johnson Matthey, 99.9\%, $400 \mathrm{~nm}$ grain size, 8\% volume) was used instead of $\mathrm{Al}_{2} \mathrm{O}_{3}$.

Samples were produced on two substrate materials: 96\% pure alumina (Kyocera, Japan, A476) as standard thick-film substrate and EN AW 6060 aluminium alloy (AlMgSi0.5) pieces. For each sample, two layers $(40 \mu \mathrm{m})$ of dielectric were first screen-printed and fired, in order to guarantee good insulation, followed by the conductor and resistor. Firing was carried out in a lamp furnace. In all cases, the firing cycle started with a dwell at $370^{\circ} \mathrm{C}$ for organic burnout, followed by rapid $\left(10^{\circ} \mathrm{C} / \mathrm{min}\right)$ heating to the peak temperature, remaining there for 20 $\mathrm{min}$. Finally, the samples were cooled down at $20 \circ \mathrm{C} / \mathrm{min}$. Firing temperatures were 525$600^{\circ} \mathrm{C}$ for dielectrics based on V6 glass, $450-525{ }^{\circ} \mathrm{C}$ for dielectrics based on V8 and $450^{\circ} \mathrm{C}$ for the resistor. The conductor was fired at $500^{\circ} \mathrm{C}$ or at the same temperature as the dielectric, whichever was lower.

Samples were produced The parameters for both resistive compositions are given in Tab. 92 . Two sample types were produced: one for measuring resistance and TCR $(1.5 \mathrm{~mm}$ wide resistors of several lengths, Fig. 1), and the other for piezoresistive gauge factor (GF, Wheatstone measurement bridge on cantilever beam, $1 \times 1 \mathrm{~mm}^{2}$ resistors). Resistor studies were carried out on both $96 \%$ pure alumina (Kyocera, Japan, A-476) as standard thick-film substrate and EN AW 6060 aluminium alloy (AlMgSi0.5) pieces.

Samples were produced for three measurements: dielectric breakdown strength, sheet resistance and TCR, and piezoresistive gauge factor of the resistor.

Samples for breakdown strength measurement consisted of $2 \mathrm{~mm}$ diameter conductor dots screen-printed onto the final dielectric layer itself screen-printed on aluminium substrates. Electric breakdown tests were carried out by applying dc and ac voltages with a ramp of $100 \mathrm{~V} / \mathrm{s}$ to maximum voltage $(5 \mathrm{kV}$ dc or $4 \mathrm{kV} \mathrm{ac})$ or breakdown. Breakdown was considered to have occurred when the current exceeded $0.1 \mathrm{~mA}$ dc or $1 \mathrm{~mA}$ ac. These samples allow measuring the dielectric constant and loss factor too.

For measuring sheet resistance and TCR (1.5 mm wide resistors of several lengths), and the piezoresistive gauge factor (GF, Wheatstone measurement bridge on cantilever beam, $1 \mathrm{~mm} \times$ $1 \mathrm{~mm}$ resistors) two sample types were produced and depicted in Fig. 1. 


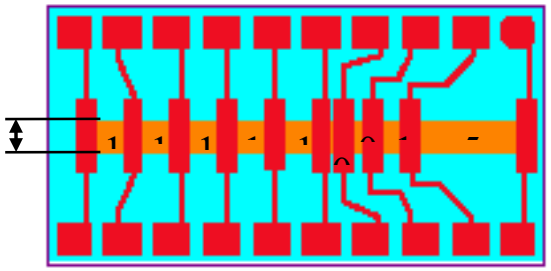

(a)

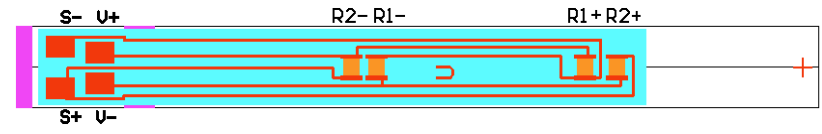

Longitudinal resistors

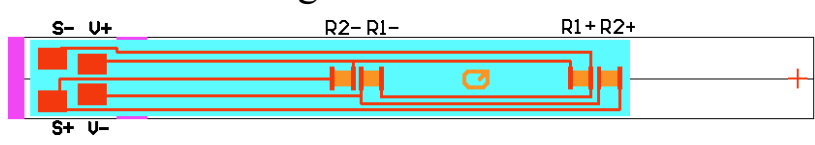

Transverse resistors

(b)

Fig. 1. Layout of the test sample for measurement of electrical properties.

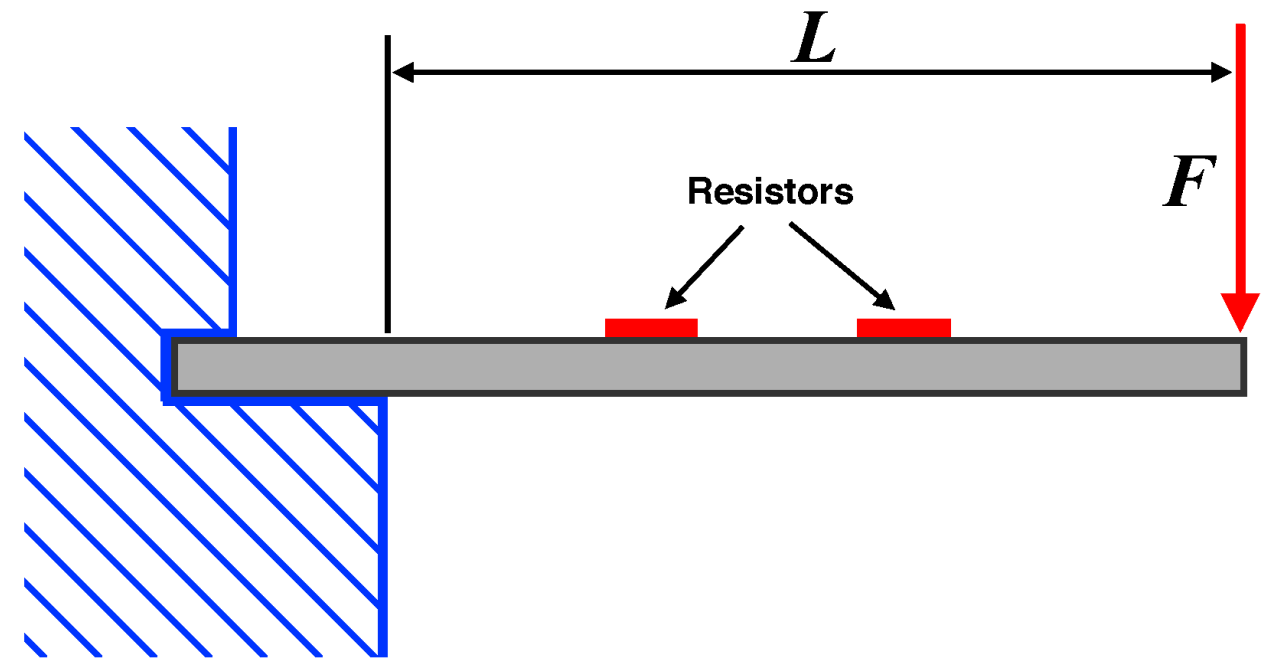

Fig. 2. Layout of the test sample for measurement of electrical properties.
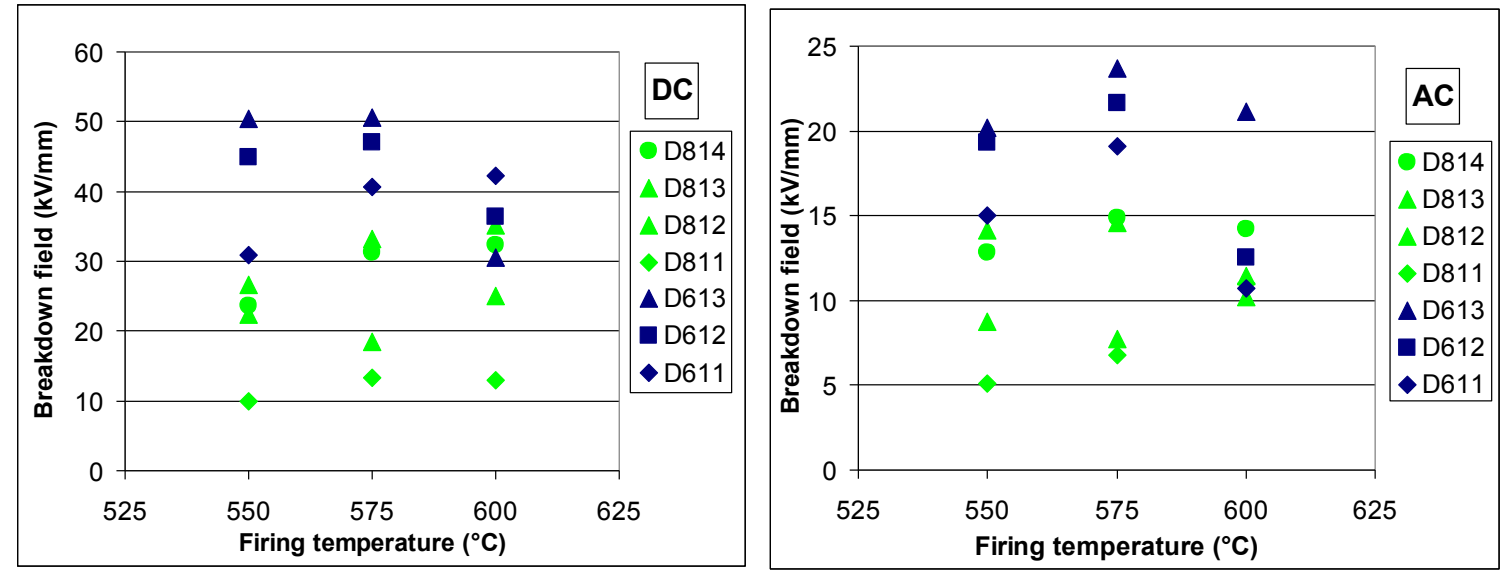

Fig. 3. Breakdown strength of dielectrics.

D6xx = V6-based; D8xx $=$ V8-based; $11-14=10 . .40 \% \mathrm{Al}_{2} \mathrm{O}_{3}$. 


\begin{tabular}{|l|l|l|}
\hline Dielectrics & Dielectric constant $\varepsilon$ & Dissipation factor D \\
\hline D613 & 10.7 & 0.018 \\
\hline D813 & 4.3 & 0.035 \\
\hline
\end{tabular}

Tab. 1: Electrical characteristics at $10 \mathrm{kHz}$ of dielectrics loaded with $30 \% \mathrm{Al}_{2} \mathrm{O}_{3}{ }^{1}$.

\begin{tabular}{|l|l|c|c|}
\hline Code & Dielectric & Alumina & Aluminium \\
\hline$\left(\mathrm{Al}_{2} \mathrm{O}_{3}\right)$ & (Alumina) & $-210 \pm 30$ & - \\
\hline $\mathrm{D} 611$ & $\mathrm{~V} 6+10 \% \mathrm{Al}_{2} \mathrm{O}_{3}$ & $-400 \pm 190$ & $-20 \pm 14$ \\
\hline $\mathrm{D} 612$ & $\mathrm{~V} 6+20 \% \mathrm{Al}_{2} \mathrm{O}_{3}$ & $-240 \pm 50$ & $-25 \pm 14$ \\
\hline $\mathrm{D} 613$ & $\mathrm{~V} 6+30 \% \mathrm{Al}_{2} \mathrm{O}_{3}$ & $-220 \pm 30$ & - \\
\hline $\mathrm{D} 811$ & $\mathrm{~V} 8+10 \% \mathrm{Al}_{2} \mathrm{O}_{3}$ & $-1900 \pm 1300$ & $+14 \pm 9$ \\
\hline $\mathrm{D} 812$ & $\mathrm{~V} 8+20 \% \mathrm{Al}_{2} \mathrm{O}_{3}$ & $-2000 \pm 1200$ & $-5 \pm 9$ \\
\hline $\mathrm{D} 813$ & $\mathrm{~V} 8+30 \% \mathrm{Al}_{2} \mathrm{O}_{3}$ & $-2400 \pm 2100$ & $-30 \pm 14$ \\
\hline $\mathrm{D} 814$ & $\mathrm{~V} 8+40 \% \mathrm{Al}_{2} \mathrm{O}_{3}$ & $-200 \pm 70$ & $-110 \pm 30$ \\
\hline
\end{tabular}

Tab. 2: TCR(ppm/K) of V8 and V6 resistors on various substrates and dielectrics ${ }^{2}$.

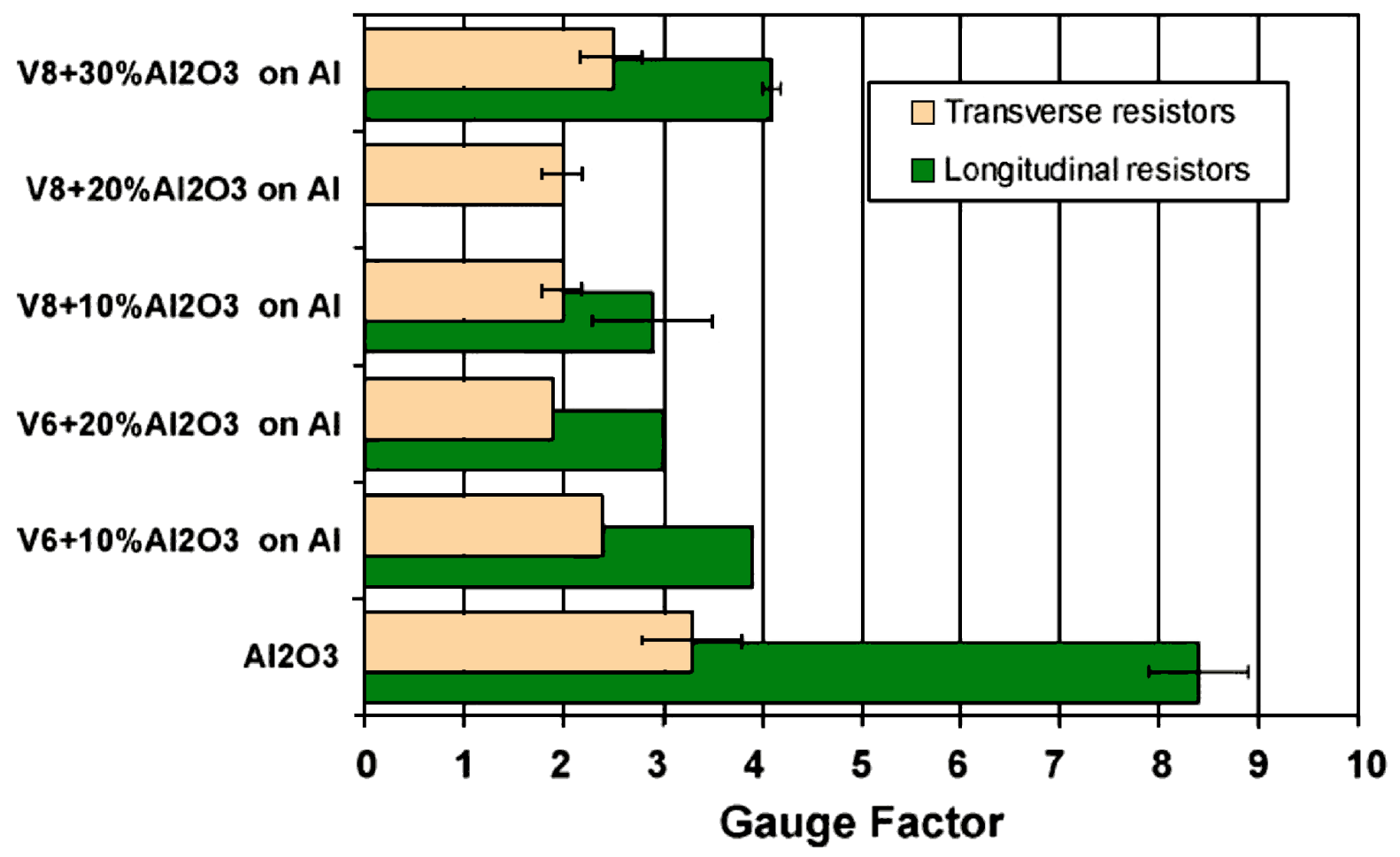

Fig. 4. Transverse and longitudinal GF according to combinations dielectrics/substrate ${ }^{3}$.

Conference version: see Tab. 94.

Conference version: see Tab. 95.

Conference version: see Tab. 96. 
Sheet resistance and TCR were measured between $30^{\circ} \mathrm{C}$ and $100^{\circ} \mathrm{C}$ using the samples depicted in Fig. 1a. GF, defined as the ratio between relative resistor change and mechanical strain, was determined at RT $\left(23 \ldots 26^{\circ} \mathrm{C}\right)$ by suspending weights at the end of the test cantilevers (Fig. 1b, Fig. 2).

\section{Results and discussion}

\subsection{Dielectric Strength}

The results are represented in Fig. 3. We can notice that, for both AC and DC voltages, dielectrics based on V6 glass have a higher resistance to breakdown than those based on V8 glass. As the V8-based samples become more "liquid" during conductor firing than the V6based ones due to the lower melting temperature of V8, we suppose this low electric breakdown resistance is due to diffusion of the conductor into the dielectric. This is confirmed by the fact that breakdown properties also improve with higher alumina powder content. In the case of D613 dielectric (V6 with 30\% alumina), we obtain very satisfactory dielectric insulation properties.

\subsection{Dielectric constant and losses}

The dielectric constants e and the dissipation factor $\mathrm{D}$ of some of the dielectrics are given in Tab. 94. V8 tends to give a lower dielectric constant and higher losses. Further work is needed to more precisely evaluate the respective contributions of glass and filler.

\subsection{Resistor value and TCR}

TCR of both resistor sets measured as a function of underlying dielectric are summarised in Tab. 95. It must be mentioned that these resistive compositions are not optimised for a given TCR value ${ }^{4}$.

On the alumina reference substrate, unreliable results were observed for the samples with dielectrics filled with low $\mathrm{Al}_{2} \mathrm{O}_{3}$ content ( $\mathrm{V} 6+10 \% \mathrm{Al}_{2} \mathrm{O}_{3}$ and $\mathrm{V} 8+10-30 \% \mathrm{Al}_{2} \mathrm{O}_{3}$ ). This is ascribed to cracking due to tensile thermal stresses arising upon cooling after firing. Theses stresses are caused by the higher values of $\alpha$ of the glasses compared to alumina. The $\alpha$ values of V6 and V8 are 9 and $11 \mathrm{ppm} / \mathrm{K}$, respectively [5], compared to ca. $7 \mathrm{ppm} / \mathrm{K}$ for alumina, but this problem is mitigated by the alumina filler. This accounts for the fact that less problems are encountered at higher filler loadings and for V6 as opposed to V8.

Resistors based on V6 glass weren't screen printed on D8xx dielectrics because of the incompatibility of their firing process. Moreover, all samples on aluminium with R6 and D611 failed due to excessive compressive thermal mismatch stresses. 
When not affected by cracking, resistor values $(10 \mathrm{k} \Omega)$ and TCR of resistors directly on alumina are very close to their values on the corresponding dielectrics, independently of the dielectric composition, which is expected from the fact that the compositions of the resistor and dielectrics glass are identical (on $\mathrm{V} 8+\mathrm{Al}_{2} \mathrm{O}_{3}$ ) or very similar $\left(\mathrm{V} 6+\mathrm{Al}_{2} \mathrm{O}_{3}\right)$, and that the dielectric filler material is identical to that of the substrate. One must also mention the low firing temperature $\left(450^{\circ} \mathrm{C}\right)$ of the resistor, which limits interdiffusion with dielectric. The firing temperature of the dielectric has no noticeable effect on the resistor properties, due to the absence of important chemical reactions within the dielectrics 5 .

On aluminium, the TCR values of R8 are positively shifted by ca. $200 \mathrm{ppm} / \mathrm{K}$ compared to on alumina. On dielectrics based on V6, no noticeable dependence of TCR on filler loading is observed. This is not the case for V8-based ones, where higher filler loadings give somewhat lower TCR values. In contrast to alumina, dielectrics on aluminium are under strong compressive stresses, which is higher for $\mathrm{V} 6$ than for $\mathrm{V} 8$ and for higher filler contents. This stress caused cracking for $\mathrm{V} 6+\mathrm{Al}_{2} \mathrm{O}_{3}$.

\subsection{Gauge factor measurement:}

The results are depicted on Fig. 4. Not all combinations could be measured, due to the abovementioned cracking problems, which are much more acute for this measurement, where the sample is subjected to mechanical stress. This is why no samples ${ }^{6}$ could be measured on alumina, except directly on the substrate.

On $\mathrm{Al}$, the resistor gauge factors are quite low $\left(\mathrm{GF}_{\mathrm{L}}=3-4\right)$, which lies in the range of previous results on similar resistors based on V6 [6]. The results directly on alumina are suspect, due to the abovementioned potential cracking problems. In fact, this sample was found to be damaged (probably cracked) after the gauge factor measurements.

\subsection{Comparison of TCR and GF on aluminium and alumina}

For a given resistor, the underlying substrate influences TCR in two ways: through chemical interaction and through thermal expansion. Chemical interaction may modify the resistor material and hence TCR, and cannot be ruled out, even with a separating dielectric.

On two substrates with different values of $\alpha$, a thermomechanical shift of TCR is expected through the gauge factors $[7,8]$ :

$$
\begin{array}{l|l}
\Delta T C R=\left(G F_{L}+G F_{T}\right) \times \Delta \alpha & \begin{array}{l}
\Delta \mathrm{TCR}: \text { expected difference of TCR between alumina and Al } \\
\mathrm{GF}_{\mathrm{L}, \mathrm{T}}: \text { longitudinal and transverse gauge factor } \\
\Delta \alpha: \text { difference of substrate thermal expansion coefficients }
\end{array}
\end{array}
$$

\footnotetext{
5 Conference paper: resistor composition R8 does not seem to be strongly affected by the V6-based (D6xx) dielectrics. On alumina, except for the cracked samples, the same TCR values are obtained directly on the substrate, on D611...643 and on D814. One must mention that V6 and V8 are not very different in composition. For crack-free samples, the resistor values were relatively independent of the dielectric used and its firing temperature. The sheet resistances of R6 and R8 were found to be ca. 35 and $10 \mathrm{kOhm}$ respectively.

6 Conference paper: some tentative measurements exist for R6 on alumina (see Tab. 96). However, the inverse problem (too high compressive stress) caused failure of R6 samples on Al.
} 
A positive shift of TCR on aluminium vs. alumina is therefore expected, as Al has a much higher value of $\alpha: 23$ vs. $7 \mathrm{ppm} / \mathrm{K}$. From our gauge factor measurements, we get: $\mathrm{GF}_{\mathrm{L}}+\mathrm{GF}_{\mathrm{T}} \cong 6$, which gives us an expected shift of ca. $+100 \mathrm{ppm} / \mathrm{K}$. This value agrees well with the shift observed on $\mathrm{V} 8+40 \% \mathrm{Al}_{2} \mathrm{O}_{3}$. On the other dielectrics, a further shift of TCR is observed, which is probably chemical in nature. This issue will be clarified in further experiments.

\section{Conclusion}

The studied experimental thick-film compositions constitute the first steps towards a lowtemperature thick-film materials system suitable for deposition on heat-sensitive substrates such as steel, glass, titanium and aluminium alloys. Good electrical insulation and first resistive and piezoresistive properties have been demonstrated.

From a processing point of view, V6-based dielectrics and dielectrics with higher alumina loading are more difficult to obtain crack-free on aluminium, as they have a lower a and a higher stress relaxation temperature, which gives rise to considerably higher thermal stresses. This is why many samples (D613 + R8 and all D6xx + R6) could not be obtained. The D8xx dielectrics are less sensitive to stress and better suited for application onto aluminium.

Future work will address the experimental problems which have troubled this study. Especially, a given thick-film system must be studied on substrates with a narrower range of a. On aluminium-based materials, this can be done by using now widely available Al-SiC and Al-Si composites. For substrates with very low (alumina, $\mathrm{Si}$ ) or high $\alpha(\mathrm{Cu}, \mathrm{Al})$, other fillers such as $\mathrm{SiO}_{2}$ or $\mathrm{CaF}_{2}$ will be explored.

\section{References}

1. White NM, A study of the piezoresistive effect in thick-film resistors and its application to load transduction, thesis, University of Southampton, Faculty of Engineering \& applied Science (1988).

2. Chien CW, Lee SL, Lin JC, Processing and properties of high volume fraction aluminium/silicon composites. Materials science and technology, 19 (9): 1231-1234.

3. Cui Y, High volume fraction $\mathrm{SiCp} / \mathrm{Al}$ composites prepared by pressureless melt infiltration: Processing, properties and applications. Composite Materials III key engineering materials, 2003, 249:45-48.

4 Prudenziati M., Handbook of sensors and actuators, 1994, chapter 1.

5 Trubnikov IL, Thermal expansion, vitrification temperature, and corrosion behaviour of lead-borosilicate glasses. Refractories and Industrial ceramics 41 (5-6) 2000.

6 Vionnet S, Grimaldi C, Maeder T, Ryser P. and Strässler S., Strain dependence of transport critical exponent in $\mathrm{RuO}_{2}$-glass systems. Ann. Phys. (Leipzig), 2004, 13(1/2), 99-100.

7 Maeder T, Grimaldi C, Ryser P, Properties of thick-film resistors on dielectric and metal substrates for piezoresistive sensors, $27^{\text {th }}$ International Conference and Exhibition of IMAPS-Poland, Podlesice, 16-19 September 2003.

8 Verma BS Sharma SK, Effect of thermal strains on the temperature coefficient of resistance, Thin Solid Films 5,R44-R46, 1970. 


\section{Appendix: Original tables of conference paper}

\begin{tabular}{|c|c|c|c|}
\hline Dielectric & Glass & Filler grain size $(\boldsymbol{\mu} \mathbf{m})$ & \%vol Alumina powder \\
\hline D611 & V6 & 10 & 10 \\
\hline D612 & V6 & 10 & 20 \\
\hline D613 & V6 & 10 & 30 \\
\hline D643 & V6 & 0.04 & 30 \\
\hline D811 & V8 & 10 & 10 \\
\hline D812 & V8 & 10 & 20 \\
\hline D813 & V8 & 10 & 30 \\
\hline D814 & V8 & 10 & 40 \\
\hline
\end{tabular}

Tab. 91: List of the studied dielectric compositions.

\begin{tabular}{|c|c|c|}
\hline Resistor & $\mathrm{R} 8$ & $\mathrm{R} 6$ \\
\hline Glass & V8 & V6 \\
\hline Grain size $\mathrm{RuO}_{2}$ particle & $\mathbf{4 0 0} \mathbf{~ n m}$ & $\mathbf{4 0} \mathbf{~ n m}$ \\
\hline $\mathrm{RuO}_{2}$ volume fraction & $\mathbf{0 . 0 8}$ & $\mathbf{0 . 0 8}$ \\
\hline Firing temperature & $\mathbf{4 5 0}^{\circ} \mathbf{C}$ & $\mathbf{5 7 5}^{\circ} \mathbf{C}$ \\
\hline
\end{tabular}

Tab. 92: Studied resistor compositions

\begin{tabular}{|c|c|c|c|c|c|c|c|}
\hline & $\mathbf{4 5 0}^{\circ} \mathbf{C}$ & $\mathbf{4 7 5}^{\circ} \mathbf{C}$ & $\mathbf{5 0 0}^{\circ} \mathbf{C}$ & $\mathbf{5 2 5}^{\circ} \mathbf{C}$ & $\mathbf{5 5 0}^{\circ} \mathbf{C}$ & $\mathbf{5 7 5}^{\circ} \mathbf{C}$ & $\mathbf{6 0 0}^{\circ} \mathbf{C}$ \\
\hline D611 & & & & $R 8$ & $R 8$ & $R 8+R 6$ & R8 + R6 \\
\hline D612 & & & & $R 8$ & $R 8$ & $R 8+R 6$ & R8 + R6 \\
\hline D613 & & & & & $R 8$ & $R 8+R 6$ & R8 + R6 \\
\hline D643 & & & & & $R 8$ & R8 + R6 & R8 + R6 \\
\hline D811 & $\mathrm{R} 8$ & $\mathrm{R} 8$ & $\mathrm{R} 8$ & & & & \\
\hline $\mathrm{D} 812$ & $\mathrm{R} 8$ & $\mathrm{R} 8$ & $\mathrm{R} 8$ & & & & \\
\hline $\mathrm{D} 813$ & $\mathrm{R} 8$ & $\mathrm{R} 8$ & $\mathrm{R} 8$ & & & & \\
\hline $\mathrm{D} 814$ & & $\mathrm{R} 8$ & $\mathrm{R} 8$ & $\mathrm{R} 8$ & & & \\
\hline
\end{tabular}

Tab. 93: Firing temperature of dielectrics and type of resistor studied. The resistors themselves were fired at $450^{\circ} \mathrm{C}(\mathrm{R8})$ and $575^{\circ} \mathrm{C}(\mathrm{R6})$. 


\begin{tabular}{|l|l|l|}
\hline Dielectrics & Dielectric constant $\varepsilon$ & Dissipation factor D \\
\hline D613 & 10.7 & 0.018 \\
\hline D643 & 15.7 & 0.018 \\
\hline D813 & 4.3 & 0.035 \\
\hline
\end{tabular}

Tab. 94: Electrical characteristics of dielectrics D6xx and D8xx, measurements obtained at $10 \mathrm{kHz}$.

\begin{tabular}{|l|c|c|c|c|}
\hline & \multicolumn{2}{|c|}{ R8 } & \multicolumn{2}{c|}{ R6 } \\
\hline & Alumina & Aluminum & Alumina & Aluminum \\
\hline (alumina) & $-210 \pm 30$ & - & $230 \pm 7$ & - \\
\hline D611 & $-400 \pm 190$ & $-20 \pm 14$ & $210 \pm 13$ & - \\
\hline D612 & $-240 \pm 50$ & $-25 \pm 14$ & $200 \pm 17$ & - \\
\hline D613 & $-220 \pm 30$ & - & $220 \pm 16$ & - \\
\hline D643 & $-240 \pm 30$ & $-29 \pm 19$ & $185 \pm 9$ & - \\
\hline D811 & $-1900 \pm 1300$ & $+14 \pm 9$ & - & - \\
\hline D812 & $-2000 \pm 1200$ & $-5 \pm 9$ & - & - \\
\hline D813 & $-2400 \pm 2100$ & $-30 \pm 14$ & - & - \\
\hline D814 & $-200 \pm 70$ & $-110 \pm 30$ & - & - \\
\hline
\end{tabular}

Tab. 95: TCR(ppm/K) of $\mathrm{V8}$ and $\mathrm{V} 6$ resistors on various substrates and dielectrics

\begin{tabular}{|c|c|c|c|c|}
\hline \multirow[t]{2}{*}{ Resistor } & \multicolumn{2}{|c|}{$\mathbf{R 8}$} & \multicolumn{2}{|c|}{ R6 } \\
\hline & $\mathbf{L}$ & $\mathbf{T}$ & $\mathbf{L}$ & $\mathbf{T}$ \\
\hline $\mathrm{Al}_{2} \mathrm{O}_{3}$ & $8.4 \pm 1.0$ & $3.3 \pm 1.0$ & $16.3 \pm 0.5$ & $18.1 \pm 0.6$ \\
\hline $\mathrm{D} 611$ on $\mathrm{Al}_{2} \mathrm{O}_{3}$ & - & - & $24.8 \pm 2.8$ & - \\
\hline $\mathrm{D} 643$ on $\mathrm{Al}_{2} \mathrm{O}_{3}$ & - & - & $22.2 \pm 1.4$ & $15 \pm 0.7$ \\
\hline D611 on $\mathrm{Al}$ & $3.9 \pm 1.2$ & $2.4 \pm 0.4$ & & \\
\hline $\mathrm{D} 612$ on $\mathrm{Al}$ & $3.0 \pm 0.1$ & $1.9 \pm 0.4$ & & \\
\hline D643 on $\mathrm{Al}$ & $3.0 \pm 0.2$ & $2.8 \pm 0.6$ & & \\
\hline D811 on $\mathrm{Al}$ & $2.9 \pm 0.5$ & $2.0 \pm 0.1$ & & \\
\hline $\mathrm{D} 812$ on $\mathrm{Al}$ & - & $2.0 \pm 0.6$ & & \\
\hline $\mathrm{D} 813$ on $\mathrm{Al}$ & $4.1 \pm 2.4$ & $2.5 \pm 0.2$ & & \\
\hline
\end{tabular}

Tab. 96: Gauge factors of combinations dielectric/substrate 